\title{
Diagnosing Maltese Organisations Using the High Performance Organisation Framework
}

\author{
André de Waal \\ HPO Center, the Netherlands
}

\author{
Silvio De Bono \\ Idea Group, Malta
}

\begin{abstract}
Malta's introduction into the EU increased the competition in the country considerably and local companies as well as foreign subsidiaries have been forced to keep up with international quality standards in operations and human resources, with mixed results. As a consequence, Maltese organisations have been looking for a holistic improvement technique. In this article we investigate whether the High Performance Organisation (HPO) Framework, a scientifically validated technique to evaluate the performance of an organisation and identify possible performance problems and improvement possibilities, is a useful technique to help Maltese organisations in this respect. The research was conducted as part of a 2-day managerial course in Malta on HPOs. Before the course started, the participants were asked to complete the internet-based HPO questionnaire on their own organisation. During the course, the HPO scores of Maltese organisations, consisting of the average of the participants' scores, were reviewed and an in-depth analysis of the scores on the HPO factors and their characteristics was made. Attention areas were identified and draft recommendations were drawn up. The content of the HPO Action Plan was discussed and ways to approach an HPO transition in Maltese organisations were reviewed. Theoretically, the research contributes to the HPO literature as it is the first study using the HPO Framework in Malta. Practically, the research results provide Maltese managers with a technique to improve their organisations considerably and make them more competitive.
\end{abstract}

Keywords: High Performance Organisations; HPO; Malta; Organisational Performance 


\section{Introduction}

Ever since joining the European Union, and because of its diversified free-market economy, Malta has been an attractive location for international business. Specifically complex manufacturing (electronics, pharmaceuticals, software development) and services (financial, gaming, shipping, information and communications technology) companies have established themselves firmly on Maltese soil (Jones, 2008). Not only because of a favorable tax environment and attractive government incentives, but especially because of the presence of a skilled, loyal, well-educated and multilingual workforce Malta became this attractive place of business (Jones, 2008). Nowadays, Malta's economic development is based on tourism and export-oriented manufacturing, causing rapid economic growth during the past decades. Over the last few years, different credit rating agencies such as Fitch have given Malta excellent credit ratings and the country has had one of the highest GDP growth when compared to other countries within the European Union. In addition, the major two political parties have somewhat converged their pro-business and at times liberal approach to business, promoting higher economic activity. In fact, during the past decade, Maltese government began promoting public-private partnerships in the healthcare sector to establish Malta as a Mediterranean health hub for medical tourism (CountryWatch Incorporated, 2020).

Malta's introduction into the EU also increased competition in the country considerably and local companies as well as foreign subsidiaries since that time were forced to keep up with international quality standards in operations and human resources (Baldacchino et al., 2003; Bezzina et al., 2017). In doing so, Maltese companies had no other option but to change their overall management approach to reflect the new realities. Maltese companies realized that in pursuit of keeping up with competition they had to upgrade their ways of working. For instance, in the field of HRM initially this was confined to personnel management executed by the company's accounting department being mainly concerned with maintaining employee records and payment and salary systems (Baldacchino et al., 2003). Since then, HRM practices have become a hybrid between performance-driven measures mixed with local culture of 'doing business' but it is considered to still be an organisational weakness (Korres et al., 2011). In addition, trade unionism has developed strongly, forcing many Maltese organisations to mainly apply a collective bargaining approach (Parnis, 2003).

The state of HRM might be symptomatic for Maltese organisations in the sense that although these organisations are doing quite well in certain areas such as procurement (Flynn, 2018) and in the Maltese public sector organisations (Lobont, et al., 2018) there is much more potential in them than hitherto expressed. Having realized this, Maltese organisations are now looking for ways to improve themselves in an holistic manner, causing a lot of change (Engel, 2018). In this article we investigate whether the High Performance Organisation (HPO) Framework, a scientifically validated technique to evaluate the performance of an organisation and identify possible performance problems and improvement possibilities is a useful technique to help Maltese organisations in this respect (de Waal, 2007, 2012; Do and Mai, 2020). The

International Journal of Management and Applied Research, 2020, Vol. 7, No. 4 
HPO Framework makes it possible for organisations to transform themselves into an HPO, defined as an organisation that achieves financial and non-financial results that are exceedingly better than those of its peer group over a period of time of five years or more, by focusing in a disciplined way on that which really matters to the organisation" (de Waal, 2010, page 10).

The remainder of this article is structured as follows. In the next sections previous HPO research conducted in Malta is discussed, after which the HPO Framework is described. This is followed by a description of our research approach and research results. Subsequently, these research results are analyzed, after which the article ends with a conclusion, limitations to the research, and opportunities for future study. Our research has both theoretical and practical contributions. Theoretically, our research contributes to the HPO literature as it is the first study - to our knowledge - of high performance in Malta. Practically, the research results provide Maltese managers with a technique to improve their organisations considerably and make them (even) better performing and (even) more competitive.

\section{High Performance Research in Malta}

We conducted a review of the academic literature on high performance in Malta, using key words such 'high performance organisations', 'high performance' and 'HPO' in combination with 'Malta'. The review did not yield any academic study on this topic in Malta. This is not to say there were not studies into improving performance in specific areas. For instance, De Bono (2003) has looked into the managerial attributes of managers in the service industry and concluded notable competency differences between owner-managers versus employee-managers. In addition De Bono and Heijden (2008) outlined critical owner-manager competencies as key attributes towards achieving organisational performance. Law and Aquilina (2013) studied how a leadership coaching program for nurse ward managers in hospitals impacted their performance, and found that 27 specific leadership attributes has a positive influence on the self-awareness, feelings of support, ability to take decisions and keep to time frames, and achievement of organisational and personal goals by the managers. Camilleri (2019) looked at attitudes of Maltese managers toward social responsibility, using the ISO 26000 social responsibility standard, and found that these managers were primarily concerned about environmental responsibility and also committed to resolving grievances and on countering corruption through social dialogue and forging relationships with stakeholders.

Montebello (2003) investigated the cultural dimensions in a Maltese semiconductor manufacturing company, using Hofstede's (1984) cultural dimensions to evaluate their effects on the creation of self-managing teams in this company; and found a low power distance which helps the creation and maintenance of self-managing teams; a neutral position with respect to individualism and collectivism which means that the Maltese are capable of working in a self-managed team but still keep the individualistic targets in mind; a high feminine society which is appropriate for the participative management required for self-managing teams; a very strong uncertainty avoidance which is not

International Journal of Management and Applied Research, 2020, Vol. 7, No. 4 
conducive for the self-managing concept; and a neutral and unbiased position with respect to Confucian dynamism which does not help nor hinder self-managing.

Buttigieg et al. (2016a) looked at ways to implement continuous quality improvement across multiple settings in a Maltese tertiary care hospital using logical framework analysis (LFA) in a case study setting, and found substantial improvement in quality across the three settings. This kind of study was repeated by Buttigieg et al. (2016b) in an accident and emergency unit of a Maltese hospital, with the same positive results. Camilleri et al. (2016), based on a case study, showed that continuous improvement in the quality of education leadership combined with social progress such as better access to childcare and more flexible working schemes can create a virtuous cycle of increased productivity and economic growth. Finally, Camilleri and van der Heijden (2007) developed a performance management model by examining relations between organisational commitment, public service motivation and employee performance, and showed through this model that employee perception of how well the organisation is managed is likely to result in higher organisational commitment, leading to a higher level of public service motivation and employee performance.

This overview of the scarce literature into organisational improvement at Maltese organisations reveals a clear gap in the current literature, not only on the number but also types of improvement studies in the Maltese context. We will address this gap by applying a holistic improvement technique, the HPO Framework (de Waal, 2012), to evaluate the current status of Maltese organisations and to come up with improvement possibilities.

\section{The HPO Framework}

The HPO framework was developed based on a descriptive literature review (Phase 1) and an empirical study in the form of a worldwide questionnaire (Phase 2) (de Waal, 2012). This questionnaire yielded 2015 responses of 1,470 organisations worldwide. Based on the collected data and applying a principal component analysis 35 characteristics, with both a significant and a strong correlation with organisational performance, were identified. In addition, with a factor analysis from these 35 characteristics five factors were extracted. The HPO research shows that there is a direct and positive relationship between the five HPO factors and competitive performance (de Waal \& Goedegebuure, 2017): the higher the scores on the HPO factors (HPO scores), the better the results of the organisation, and the lower the HPO scores the lower the competitive performance. The five HPO factors are described underneath (based on de Waal, 2020).

\subsection{Management Quality}

HPO managers maintain trust relationships with their employees, by showing appreciation for their loyalty, treating them with attention and respect, and developing and sustaining a good relationship with them. They encourage employees to have faith and trust in themselves and others, and they treat them in a fair and honest manner. They have integrity and are a role model for employees and colleague managers. Through their honesty, sincerity, dedication, enthusiasm, respectful attitude, strong

International Journal of Management and Applied Research, 2020, Vol. 7, No. 4 
ethical values, credibility and consistent behaviour. They are not afraid to show their weaknesses and neither are they complacent nor arrogant. They are decisive, avoid "paralysis by analysis", and propose quick and effective actions while stimulating others to also act. HPO managers coach and facilitate employees in such a way that these can achieve better performance. They support, help and protect employees from outside influences, when and where necessary. They are always approachable for their employees. At the same time, they hold their employees responsible for their results and take corrective action when they do not perform well. They put their focus on achieving results, underline to employees the responsibility for their own performance, and are not afraid to take the difficult decisions (such as firing a person). They have an effective, self-assured and strong management style, developed through the continuous communication of the values of the organisation and making sure that all their employees know the organisational strategy and support that strategy. Where necessary, HPO managers coach their employees in letting their own activities contribute to the achievement of the organisational strategy.

\subsection{Openness and Action Orientation}

An HPO has an open culture, which means that there is a lot of dialogue between managers and employees and among employees themselves, to exchange knowledge and experiences, increase commitment to the organisation, and to create clarity on all organisational levels about what is important for the organisation and what it wants to achieve. Managers explicitly ask for the opinions and ideas of their employees and act on that information. There is a lot of mutual respect and everybody is asked to get involved in the important affairs of the organisation. There is room for experimentation and failure in the organisation and there is no fear of taking (calculated) risks and making mistakes (as long as these are not repeated mistakes): these are seen as opportunities for learning. People give each other honest and sincere feedback with the goal to make things better, and this feedback is received as such. Knowledge is not power in an HPO, shared knowledge is. The HPO culture is actiondriven. There is good, deep thinking about issues but HPOs do not suffer from "paralysis by analysis." They do not overanalyze but balance thought and action. Thus they take enough time for adequate decision-making but then turn their decisions quickly into actions to solve problems immediately. As a consequence, decisions can be made even though these are not optimal and people realize they might have to adjust these decisions and chosen course of action based on new information which becomes available because action was taken.

\subsection{Long-Term Orientation}

For an HPO long-term survival and contribution to stakeholders is much more important than short-term successes for shareholders. The organisation and its people are extremely client-oriented: they listen carefully to what clients want and need, they understand the values and interests of clients, build excellent long-term relationships with them and have regularly direct contact with them. HPOs involve clients directly in the organisation's affairs (such as development of new products and services, or the best way to perform new tasks), are open to their reactions, and aim to increase the value for clients. Their basic attitude is that every party that comes into contact with

International Journal of Management and Applied Research, 2020, Vol. 7, No. 4 
the organisation should have a good feeling about the interaction because the organisation added value to them and made things just a bit better for them, and if this is the case it is only natural for the organisation to exists as long as possible to make as many parties as happy as possible for as long as possible. The organisation trains and grooms its people in such a way that new management can be promoted from within. Most managers have worked for a long time in the organisation, albeit in different positions and possibly different locations, and thus know the organisation, its stakeholders, its products and services, its employees and its industry very well. And because they are HPO managers they can use this knowledge to good effect. HPOs are also a secure workplace, both in the physical as the psychological way. Regarding the latter, people can make mistakes without having to be afraid for being fired. In fact, making staff redundant is the last resort for an HPO.

\subsection{Continuous Improvement and Renewal}

HPOs have a strategy that is unique, either in content ("what the organisation wants to achieve") or in execution ("how the organisation does things") or (ideally) in both. This means that it is very clear for (potential) clients why they should go to this organisation and not to other comparable organisations in the sector. An HPO also keeps developing new strategies for those strategies that are no longer unique or no longer working. The organisation then does it utmost to put this unique strategy into practice. It improves, simplifies and aligns the processes in the organisation so it can act quickly and effectively on changing circumstances. Unnecessary procedures and tasks are removed and information overload is combated. The organisation does track the information that really matters, by using critical success factors and key performance indicators. It also tracks precisely whether objectives still contribute to the organisation's strategy and goals and whether they are fulfilled. Difficult issues are reported immediately to both managers and employees so they can deal with these quickly, and improve the way the organisation is working. An HPO feels a moral obligation to continuously strive for the best results, for its clients and its stakeholders. To this end, products, processes and services are continuously improved and renewed. This is supported by a commitment to strengthen continuously the core competencies of the organisation and its people.

\subsection{Employee Quality}

An HPO has a diverse and therefore complementary workforce. New people are hired that already have HPO traits, such as a high degree of flexibility and resilience needed to recognize and address organisational problems in a creative way. At the same time these new hires will have different skills from the current workforce so that continuously new competencies are added to the organisation's skill base. People are continuously developed, through formal and informal training, on-the-job training, coaching, and through working with other organisations. Regarding the latter there is an explicit goal to create High Performance Partnerships (HPPs). In this kind of environment employees want, supported by their managers, to achieve extraordinary results for which they want to be held accountable and receive feedback on.

International Journal of Management and Applied Research, 2020, Vol. 7, No. 4 
An organisation can evaluate its high performance level and identify challenges and possible improvements by conducting an HPO diagnosis. The HPO diagnosis process starts with management and employees completing the HPO Questionnaire, which consists of statements based on the 35 HPO characteristics. Respondents rate their organisation on a scale of 1 (not at all) to 10 (very much so) on these statements. The individual scores are averaged to provide scores on the HPO factors for the complete organisation. These average scores indicate which HPO factors and characteristics the organisation needs to improve in order to become an HPO.

\section{Results}

The research was conducted as part of a 2-day course on high performance organisations, organized jointly in Malta by the companies of the authors. The course was aimed at managers of Maltese based organisations, both domestic and foreign. Table 1 provides some information on the participants.

\begin{tabular}{cc} 
Table 1: Information on the workshop participants \\
\hline Characteristics & Number \\
\hline Profit sector & 13 \\
Government sector & 5 \\
Female & 7 \\
Male & 11 \\
CEO & 5 \\
Higher management & 10 \\
Middle management & 3 \\
Tenure < 3 years & 3 \\
Tenure 3-5 years & 4 \\
Tenure 6-10 years & 6 \\
Tenure > 10 years & 5 \\
Age $<40$ years & 6 \\
Age 40-50 years & 6 \\
Age $>50$ years & 6 \\
\hline
\end{tabular}

Before the course started, the participants were asked to complete the internet-based HPO questionnaire on their own organisation. During the first day of the course, the need for creating HPOs was discusses. The development process of the HPO Framework was explained, and special attention was given to the financial and nonfinancial benefits of applying the HPO Framework. The HPO scores of Maltese organisations, consisting of the average of the participants' scores, were reviewed. Figure 1 gives these scores, compared to the average score of managers residing in other European countries, as collected in the HPO database of the HPO Centre. The Appendix provides the detailed scores for the HPO characteristics.

International Journal of Management and Applied Research, 2020, Vol. 7, No. 4 
Figure 1: HPO scores of Maltese organisations, compared to European organisations

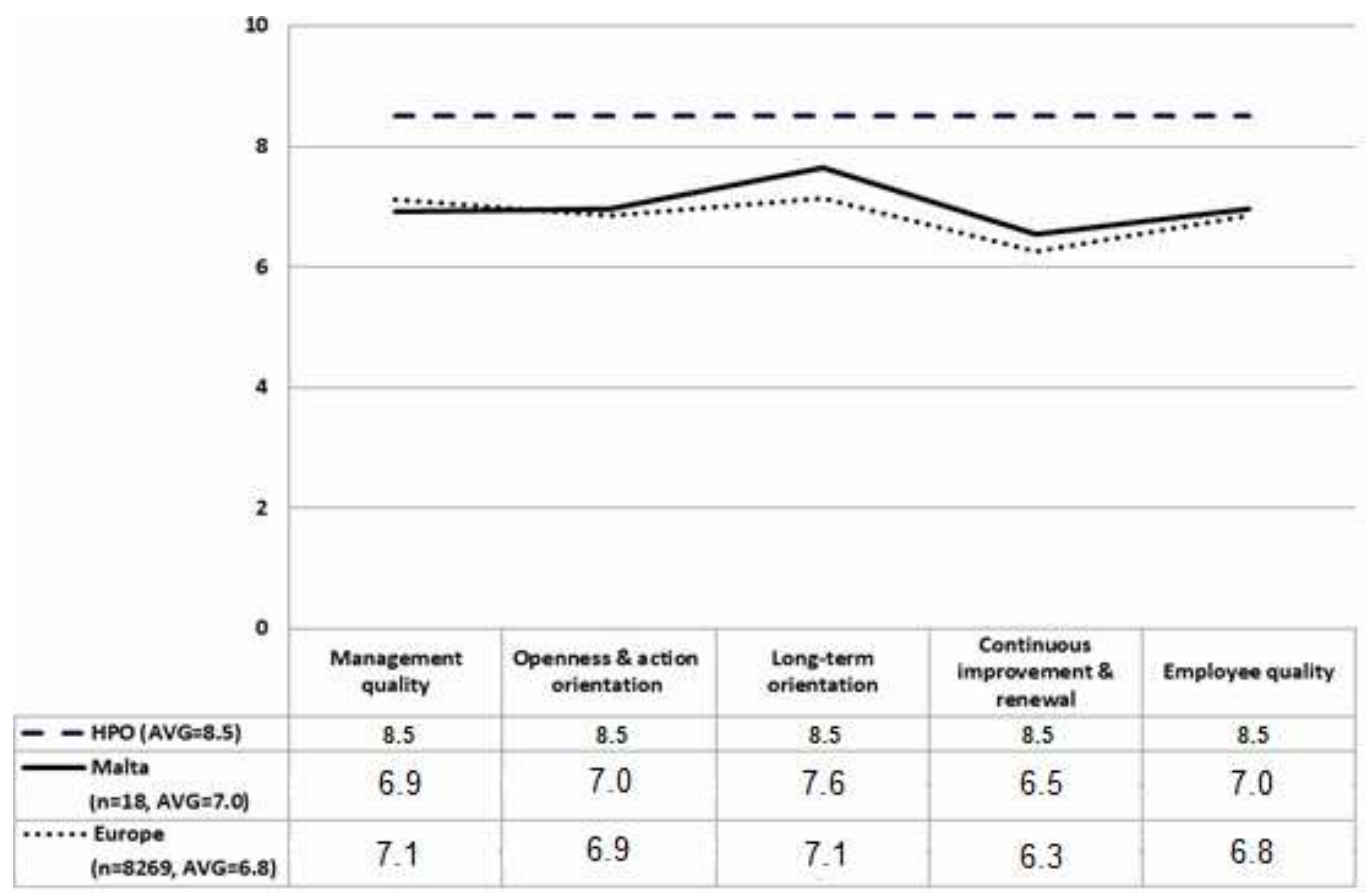

Figure 2 provides a breakdown of the HPO scores for the Maltese government and private sector organisations.

Figure 2: HPO scores of Maltese public and private sector organisations

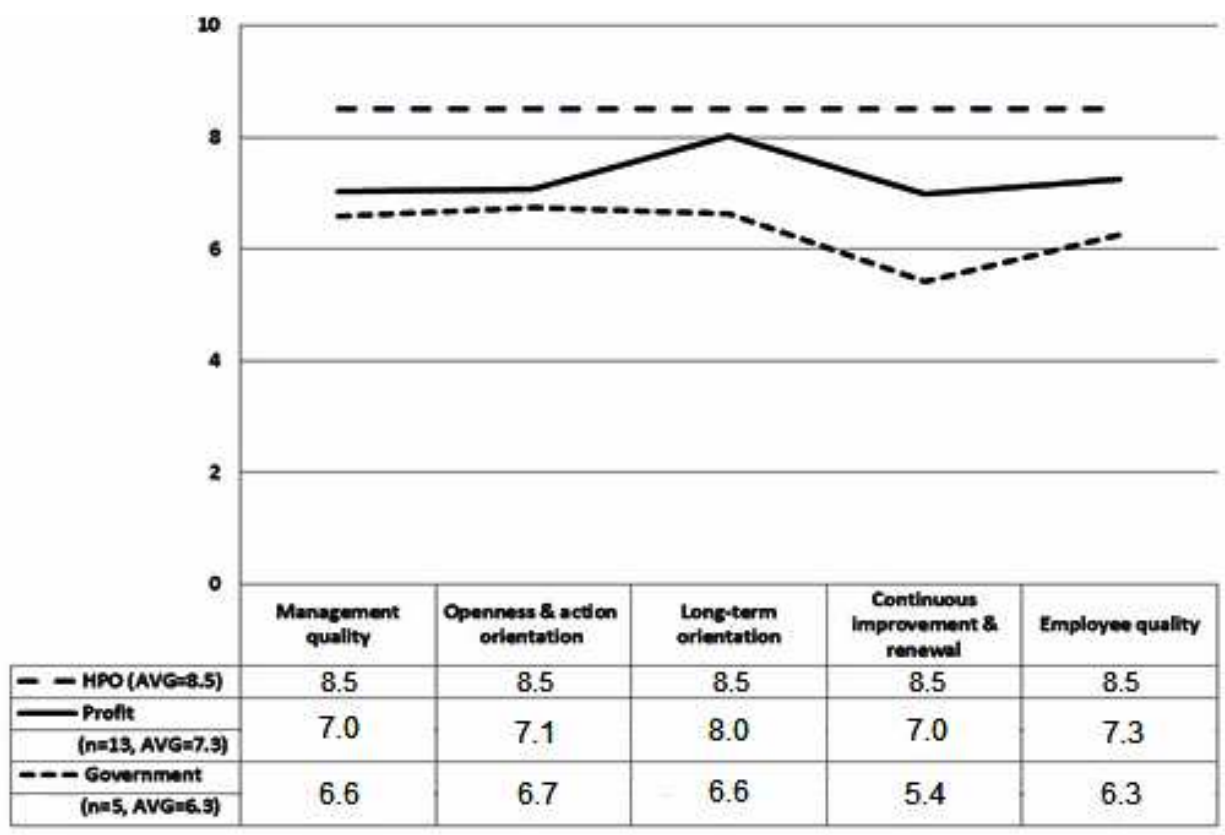

International Journal of Management and Applied Research, 2020, Vol. 7, No. 4 
Figure 1 shows that Maltese organisations are typical European organisations as the HPO profiles (i.e. the shape of the graphs) is almost the same. At the same time, the Maltese organisations score slightly higher than the European average, with the biggest difference to be found for HPO factor Long-Term Orientation. This could be explained by the research population: it can be expected that the participants to the HPO course work for organisations that have an above-average interest in the topic and already work on continuous improvement. Figure 2 shows that Maltese profit sector companies score higher that Maltese public organisations (i.e., are further along to the HPO status) which is in line with how these sectors score in general in other European countries (Linker and de Waal, 2019).

During the second course day, the participants in groups conducted the HPO Diagnosis. This consisted of an in-depth analysis and discussion of the scores on the HPO factors and characteristics. Attention areas were identified and draft recommendations were drawn up. The content of the HPO Action Plan was discussed and ways to approach an HPO transition in Maltese organisations were reviewed. Each group gave a presentation on their analysis, and the other groups gave positive feedback on these presentations. Subsequently all presentations were analyzed, to find generic HPO issues and attention points for Maltese organisations. These are discussed in the next section.

\section{Analysis}

During the workshop the participants discussed, per each HPO factor, the underlying causes for the HPO scores and specifically looked for areas to improve. Subsequently, they came up with recommendations for improvement. Underneath the results of the discussions are arranged per HPO factor. In addition, there is a brief paragraph on the proposed roll-out of HPO in Maltese organisations. We have added several literature references where we found a match between the participants, analysis and the literature.

\subsection{Management Quality}

The long history of colonialism has caused an inherent mistrust in people, especially authority figures, so it is difficult for top executives to be seen as having high integrity and high quality. This history also made people more cautious in making fast decisions, aggravated by the Mediterranean culture which creates a bit of a laissez-fair attitude and "more talk, less action" in the country (Jones, 2008). This is especially felt in government where there is a lack of decisiveness and action-taking, created amongst others by much red tape. Also the strong unions do not help managers to be able to take quick decisions and action, and being effective. As Malta is a country where everyone knows each other it is difficult to promote someone without creating envy so people stay too long in the same position. This makes it difficult to enhance a growth mindset. An extra complication is that many positions of higher management in Maltese organisations are occupied by foreigners.

To increase the quality of Maltese managers, the participants gave the following suggestions:

International Journal of Management and Applied Research, 2020, Vol. 7, No. 4 
- Create more trust in management by conducting more frequent and more open dialogue with employees. Show more empathy towards employees.

- As management, start acting more as a team that sets the direction for the organisation and that functions as a role model for employees.

- Engage unions more in decision-making.

- Develop more competencies in HR skills, such as coaching and motivating employees.

- Start managing by walking around and knowing your employees.

- Involve lower-level managers and employees in setting budgets and action plans.

\subsection{Openness and Action-Orientation}

In many Maltese organisations there exists a power culture based on control and rules, with one-way top-down communication and no dilution of control. This creates a culture where people are afraid of making mistakes because of their consequences. In addition there is fear to own up to mistakes. There also exist, especially among management, a belief that "our Maltese ways are correct" and an attitude of "we already know enough." This creates an atmosphere of complacency and is not conducive to learning. Also, there is a silo-mentality between the various departments in Maltese organisations which prevents effective cooperation. At the same time, Maltese people are not afraid to express themselves by using body language and expressive behaviour, as Malta has an affective culture. This means that Maltese people, certainly in the family environment, are more open than in the business environment (Trompenaars and Hampden-Turner, 1997).

To increase the openness and action-orientation in Maltese organisations, the participants gave the following suggestions:

- Regularly organize round table discussion with no 'Head' and thus open and direct dialogue.

- Spend more time on team building activities.

- Regularly discuss case studies about things that happened in the organisation and regularly conduct peer reviews, to increase knowledge sharing.

- Involve employees more in the organisation's affairs as this will create innovation and more ideas for improvement.

- Create official channels through which employees can receive and give feedback.

- Build a skill matrix and identify gaps by employee. Then organize formal training sessions and workshops, on-the-job training, one-to-one mentoring, a mentor/mentee program, tailored to the needs of individual employees.

- Also evaluate the impact of new skills; learn from feedback from employees, management and customers.

- Foster an attitude of "Think not outside the box ... but think as if there was no box!" as one of the workshop participants put it succinctly.

\subsection{Long-Term Orientation}

There is a mentality of money-making (i.e. immediate profit) and a situation of limited competition in the Maltese marketplace which does not help the customer orientation of employees (Jones, 2008). This creates also a situation where stakeholders in general do not see the organisation as partner. Positions of people in the organisation are

International Journal of Management and Applied Research, 2020, Vol. 7, No. 4 
secure due to the Unions' intervention and their power, which again creates complacency and an attitude of taking things for granted. This is strengthened as there are in general limited opportunities for promotion from within. It is often more about 'who you know' and pleasing someone in a higher role which advances one's career (Engel, 2018).

To increase the long-term orientation of Maltese organisations, the participants gave the following suggestions:

- Increase external exposure though participating in fairs and exhibitions, and networking,

- Make clear to employees that internal career development exists, which also show job security.

\subsection{Continuous Improvement and Renewal}

In general there is a lot of firefighting going on in Maltese organisation. There is no vision or strategy to structurally deal with problems nor an innovation strategy. Thus there is hardly any investment in R\&D. This is aggravated by the lack of market knowledge among many managers. There is in general a lot of resistance to change as many Maltese organisations are or act as traditional family businesses. People also often miss the skills to improve and innovate as HR training is viewed as a cost. In general there is a lack of discipline in the execution of improvement projects, a lack of indicators to track performance and even when these indicators are present they are hardly ever used.

To increase continuous improvement and renewal in Maltese organisations, the participants gave the following suggestions:

- Use a clear method to measure performance: KPIS, objectives, causal relationships, regular feedback/performance reviews.

- Create long-term plans for all departments in which needs are prioritized, budgets are clear, the way to execute plans are clear, and analysis and evaluation moments are incorporated.

- Regularly share non-sensitive information, such as departmental budgets, KPI results, the organisation's vision and future plans, the intended introduction of new technologies, products and/or services.

- Get to know what information employees need and want, and how they would like to receive this information.

- Identify the core competencies of the organisation and link these to the performance of the organisation. Strengthen these core competencies regularly in workshops and further build them through feedback and dialogue.

- Clearly inform employees about the organisation's short and long term objectives through workshops.

\subsection{Employee Quality}

Again referring to the Maltese history many people, although used to dealing with ambiguity and the unknown, in their working life are not very flexible, which is reflected in them tending to stay after their studies at the same organisations for a long time (Jones, 2008). In general it is difficult to move anyway because of the small size

International Journal of Management and Applied Research, 2020, Vol. 7, No. 4 
of this island causes a lack of opportunities. Employees are not being inspired, either by their managers or by training (which is not industry-driven enough to often not very relevant), resulting in low motivation and ability to be flexible or to contribute to partnerships. At the same time, employees show great loyalty and are rewarded for that, sometimes more than for their competence (Engel, 2018). Employees are willing to work extra hours without complaints when asked to do so by management. At the same time, if there are problems during production, employees will wait for management to fix these problems without taking own initiative.

To increase the quality of Maltese employees, the participants gave the following suggestions:

- Provide more training / coaching / mentoring to employees.

- Develop more leadership skills in employees and strengthen their emotional intelligence.

- Move as management away from the command \& control style and empower employees.

- Make sure that employees know what is expected from them, how they are performing, and what they can do to improve. If they are performing under-par, apply dialogue/feedback, give support (resources, training, guidance), and if needed give clear repercussions.

- Recognize employees' achievement.

- Instill an attitude in employees of "always do the right things for the organisation."

\section{$\underline{\text { Roll-Out }}$}

According to the participants, the following activities should take place as part of the HPO roll-out in their organisations:

- Managers should receive an introductory training on HPO so they can familiarize themselves with the concept and its intended introduction.

- Internal marketing of the HPO concept at all organisational levels should take place.

- Hygiene factors must be catered for prior to the HPO roll-out.

- Managers should be emphatically involved in the HPO roll-out by being present during all HPO interventions, partaking in setting and measuring performance, identifying competencies, knowledge sharing, and regular dialogue with HPO Coaches and employees (walk around).

- Create a HPO core team of voluntary coaches who will help colleagues organize HPO interventions (de Waal, 2012). Ensure that the HPO core team meets regularly to monitor / measure/ control / revise plans over time.

- Design and create a series of mini-projects to be executed by cross-functional teams with employees tackling different factors in their areas.

- Introduce opportunities to acknowledge / appreciate / celebrate successes during the HPO roll-out.

\section{Conclusion}

In this article we investigated whether the HPO Framework would be a helpful technique for Maltese organisations to evaluate their performance, identify possible performance problems and come up with improvement possibilities. Using a

International Journal of Management and Applied Research, 2020, Vol. 7, No. 4 
questionnaire we were able to construct the HPO profile of the average Maltese organisation and then during a 2-day course with 18 managers working at Maltese public and private sector organisations we discussed this profile and the scores on the HPO characteristics, to identify areas of attention and come up with recommendations. After the course all participants filed-in an evaluation form, which showed that 100 percent of them found the HPO Framework a very useful technique to gauge their organisations in order to generate improvement ideas. In this respect, we can state with confidence that a positive answer can be given on the question whether the HPO Framework is applicable and useful for Maltese organisations.

There are several limitations to our research, which at the same time offer opportunities for future research. Obviously, more respondents from Maltese organisations are needed to improve the generalization of our study results. In addition, getting the perspective of employees, both in the questionnaire and in the course, would have increased our insight into Maltese organisations so employees should emphatically be included in further studies. Another type of participant that was missing form our sample were respondents from the non-profit sector, specifically healthcare, so these should also be included in future research. A final opportunity for research is to conduct a longitudinal study into the effects on organisational performance of the improvements, suggested in this article, when they are actually implemented in Maltese organisations.

\section{References}

1. Baldacchino, G., Caruana, A. and Grixti, M. (Eds.) (2003), Managing people in Malta, Malta: Agenda Publishers \& Foundation for Human Resources Development.

2. Bezzina, F., Cassar, V., Tracz-Krupa, K., Przytuła, S. and Tipurić, D. (2017), "Evidence-based human resource management practices in three EU developing member states: Can managers tell truth from fallacy?", European Management Journal, Vol. 35, No. 5, pp. 688-700. https://doi.org/10.1016/j.emj.2017.02.010

3. Buttigieg, S.C., Gauci, D. and Dey, P. (2016a), "Continuous quality improvement in a Maltese hospital using logical framework analysis", Journal of Health Organisation and Management, Vol. 30, No. 7, pp. 1026 - 1046. https://doi.org/10.1108/JHOM-11-2015-0185

4. Buttigieg, S.C., Dey, P.K. and Cassar, M.R. (2016b), "Combined quality function deployment and logical framework analysis to improve quality of emergency care in Malta", International Journal of Health Care Quality Assurance, Vol. 29 No. 2, pp. 123-40. https://doi.org/10.1108/IJHCQA-04-2014-0040

5. Camilleri, E. and van Der Heijden, B. I. J. M. (2007), "Organisational Commitment, Public Service Motivation, and Performance within the Public Sector", Public Performance \& Management Review, Vol. 31 No. 2, pp. 241-274. https://doi.org/10.2753/PMR1530-9576310205

6. Camilleri, M.A. (2019), "Measuring the corporate managers' attitudes towards ISO's social responsibility standard", Total Quality Management \& Business

International Journal of Management and Applied Research, 2020, Vol. 7, No. 4 
Excellence, $\quad$ Vol. $30, \quad$ No. 13/14, $\quad$ pp. 1549-1561. https://doi.org/10.1080/14783363.2017.1413344

7. Camilleri, M.A. and Camilleri, A. (2016), "Education and social cohesion for economic growth", International Journal of Leadership in Education, Vol. 19 Issue 5, pp. 617-631. https://doi.org/10.1080/13603124.2014.995721

8. CountryWatch Incorporated (2020), Malta Country Review 2020, CountryWatch Incorporated, pp. 1-335.

9. De Bono, S. (2003), Assessing Managerial Attributes Case Study of Maltese Managers in the Service Industry, DBA Dissertation, Maastricht School of Management, Maastricht, the Netherlands.

10. De Bono, S. and van Der Heijden (2008), "Ownership Status and the Prevalence of Managerial Responsibilities and Functions. A Study among Managers in the Maltese Service Industry", Journal of Applied Management and Entrepreneurship, Vol. 13, No. 4, pp. 3-22.

11. de Waal A. A., (2007), "The Characteristics of a High Performance Organisation", Business Strategy Series, Vol. 8, No. 3, pp. 179-185. https://doi.org/10.1108/17515630710684178

12. de Waal, A. A. (2012), What Makes a High Performance Organisation: Five Validated Factors of Competitive Advantage that Apply Worldwide, Enfield: Global Professional Publishing.

13. de Waal, A. A. and Goedegebuure, R. (2017), "Investigating the causal link between a management improvement technique and organisational performance: The case of the HPO framework", Management Research Review, Vol. 40, No. 4, pp. 429-450. https://doi.org/10.1108/MRR-03-2016-0058

14. Do, T. and Mai, N. (2020), "High-performance organisation: a literature review", Journal of Strategy and Management, Vol. 13, No. 2, pp. 297-309. https://doi.org/10.1108/JSMA-11-2019-0198

15. Engel, M. (2018), "Malta: An island of secrets and lies", New Statesman, [Online] Available from: https://www.newstatesman.com/world/europe/2018/02/maltaisland-secrets-and-lies [Accessed on 5 July 2020].

16. Flynn, A. (2018), "Measuring procurement performance in Europe", Journal of Public Procurement, Vol. 18, No. 1, pp. 2-13. https://doi.org/10.1108/JOPP-032018-001

17. Hofstede, G. (1984), Culture's consequences: International differences in workrelated values, California: Sage.

18. Jones, S. (2008), "Conducting business in Malta: A brief for international managers", Global Business and Organisational Excellence, Vol. 27, No. 6, pp. 58-77. https://doi.org/10.1002/joe.20231

19. Korres, G.M., Tsobanoglou, G.O. and Kokkinou, A. (2011), "Innovation Geography and Regional Growth in European Union", SAGE Open, https://doi.org/10.1177/2158244011413142

International Journal of Management and Applied Research, 2020, Vol. 7, No. 4 
20. Law, H. and Aquilina, R. (2013), "Developing a healthcare leadership coaching model using action research and systems approaches - a case study: Implementing an executive coaching programme to support nurse managers in achieving organisational objectives in Malta", International Coaching Psychology Review, Vol. 8, No. 1, pp. 54-71.

21. Linker, P.J. and de Waal, A. (2019), De high performance overheidsorganisatie, een andere benadering van effectief verbeteren [The high performance governmental organisation, a different approach to effective improvement], Van Duuren Management, Culemborg.

22. Lobont, O.R., Moldovan, N.C., Bociu, A., Chis, C. and Brîndescu Olariu, D. (2018), "A factor analysis of the public sector performance. Significant differences between old and new EU countries", Economic Computation \& Economic Cybernetics Studies \& Research, Vol. 52, No. 2, pp. 139-156. https://doi.org/10.24818/18423264/52.2.18.09

23. Montebello, L. (2003), "Investigating cultural dimensions in a semiconductor manufacturing company in Malta", Cross Cultural Management: An International Journal, Vol. 10, No. 4, pp. 61-70. https://doi.org/10.1108/13527600310797694

24. Parnis, D. (2003), "Implementing performance management." In: Baldacchino, G., Caruana, A, and Grixti, M. (Eds.), Managing people in Malta, Malta: Agenda Publishers \& Foundation for Human Resources Development, pp. 151-166.

25. Trompenaars, F., \& Hampden-Turner, C. (1997), Riding the waves of culture: Understanding cultural diversity in business, London: Nicholas Brealey.

\section{Appendix}

This appendix provides the average scores for the HPO factors and their characteristics of the participating Maltese organisations.

\begin{tabular}{|c|c|c|c|}
\hline HPO factors & & HPO characteristics & Score \\
\hline $\begin{array}{l}\text { continuous } \\
\text { improvement }\end{array}$ & 1 & $\begin{array}{l}\text { Our organisation has adopted a strategy that sets it clearly } \\
\text { apart from other organisations. }\end{array}$ & 6.4 \\
\hline $\begin{array}{l}\text { continuous } \\
\text { improvement }\end{array}$ & 2 & In our organisation processes are continuously improved. & 6.9 \\
\hline $\begin{array}{l}\text { continuous } \\
\text { improvement }\end{array}$ & 3 & In our organisation processes are continuously simplified. & 6.7 \\
\hline $\begin{array}{l}\text { continuous } \\
\text { improvement }\end{array}$ & 4 & In our organisation processes are continuously aligned. & 6.4 \\
\hline $\begin{array}{l}\text { continuous } \\
\text { improvement }\end{array}$ & 5 & $\begin{array}{l}\text { In our organisation everything that matters to the } \\
\text { organisation's performance is explicitly reported. }\end{array}$ & 6.4 \\
\hline $\begin{array}{l}\text { continuous } \\
\text { improvement }\end{array}$ & 6 & $\begin{array}{l}\text { In our organisation both financial and non-financial } \\
\text { information is reported to organisational members. }\end{array}$ & 6.3 \\
\hline $\begin{array}{l}\text { continuous } \\
\text { improvement }\end{array}$ & 7 & $\begin{array}{l}\text { Our organisation continuously innovates its core } \\
\text { competencies. }\end{array}$ & 6.2 \\
\hline $\begin{array}{l}\text { continuous } \\
\text { improvement }\end{array}$ & 8 & $\begin{array}{l}\text { Our organisation continuously innovates its products, } \\
\text { processes and services. }\end{array}$ & 7.1 \\
\hline $\begin{array}{l}\text { openness \& action } \\
\quad \text { orientation }\end{array}$ & 9 & $\begin{array}{l}\text { My manager frequently engages in a dialogue with } \\
\text { employees. }\end{array}$ & 7.2 \\
\hline openness \& action & 10 & Organisational members spend much time on knowledge & 6.0 \\
\hline
\end{tabular}

International Journal of Management and Applied Research, 2020, Vol. 7, No. 4 
orientation openness \& action orientation openness \& action orientation openness \& action orientation openness \& action orientation management quality

management quality management quality

management quality

management quality

management quality

management quality management quality

management quality

management quality management quality management quality

workforce quality

workforce quality

workforce quality

workforce quality

long-term

orientation

long-term

orientation

long-term

orientation

long-term

orientation

long-term orientation exchange and learning from each other.

Organisational members are always involved in important processes.

12 My manager allows making mistakes.

13 My manager welcomes change.

14 Our organisation is performance driven.

15 My manager is trusted by organisational members.

16 My manager has integrity.

17 My manager is a role model for organisational members.

18 My manager applies fast decision making.

19 My manager applies fast action taking.

My manager coaches organisational members to achieve better results.

21 My manager focuses on achieving results.

22 My manager is very effective.

23 My manager applies strong leadership.

24 My manager is confident.

25 My manager is decisive with regard to non-performers.

My manager always holds organisational members responsible for their results.

My manager inspires organisational members to accomplish extraordinary results.

Organisational members are trained to be resilient and flexible.

29 Our organisation has a diverse and complementary workforce.

7.3

Our organisation grows through partnerships with suppliers and/or customers.

Our organisation maintains good and long-term relationships with all stakeholders.

Our organisation is aimed at servicing the customers as best as possible.

33 My manager has been with the company for a long time.

34 New management is promoted from within the organisation.

Our organisation is a secure workplace for organisational members. 